University of Nebraska - Lincoln

DigitalCommons@University of Nebraska - Lincoln

Publications, Agencies and Staff of the U.S.

Department of Commerce

U.S. Department of Commerce

2010

\title{
ADVERSE OUTCOME PATHWAYS AND ECOLOGICAL RISK ASSESSMENT: BRIDGING TO POPULATION-LEVEL EFFECTS
}

Vincent J. Kramer

Dow AgroSciences, vjkramer@dow.com

Matthew A. Etterson

U.S. Environmental Protection Agency

Markus Hecker

ENTRIX

Cheryl A. Murphy

Michigan State University

Guritno Roesijadi

Pacific Northwest National Laboratory

See next page for additional authors

Follow this and additional works at: https://digitalcommons.unl.edu/usdeptcommercepub

Part of the Environmental Sciences Commons

Kramer, Vincent J.; Etterson, Matthew A.; Hecker, Markus; Murphy, Cheryl A.; Roesijadi, Guritno; Spade, Daniel J.; Spromberg, Julann A.; Wang, Magnus; and Ankley, Gerald T., "ADVERSE OUTCOME PATHWAYS AND ECOLOGICAL RISK ASSESSMENT: BRIDGING TO POPULATION-LEVEL EFFECTS" (2010).

Publications, Agencies and Staff of the U.S. Department of Commerce. 217.

https://digitalcommons.unl.edu/usdeptcommercepub/217

This Article is brought to you for free and open access by the U.S. Department of Commerce at DigitalCommons@University of Nebraska - Lincoln. It has been accepted for inclusion in Publications, Agencies and Staff of the U.S. Department of Commerce by an authorized administrator of DigitalCommons@University of Nebraska - Lincoln. 


\section{Authors}

Vincent J. Kramer, Matthew A. Etterson, Markus Hecker, Cheryl A. Murphy, Guritno Roesijadi, Daniel J. Spade, Julann A. Spromberg, Magnus Wang, and Gerald T. Ankley 


\title{
Predictive Ecotoxicology Workshop
}

\section{ADVERSE OUTCOME PATHWAYS AND ECOLOGICAL RISK ASSESSMENT: BRIDGING TO POPULATION-LEVEL EFFECTS}

\author{
Vincent J. Kramer, $* \dagger$ Matthew A. Etterson, $\ddagger$ Markus Hecker, $§$ Cheryl A. Murphy, „| Guritno Roesijadi,\# \\ Daniel J. Spade, $\dagger \dagger$ Julann A. Spromberg, $\nmid \ddagger$ Magnus Wang, $\S \S$ and Gerald T. Ankley \\ †Dow AgroSciences, Indianapolis, Indiana, USA \\ $\ddagger$ U.S. Environmental Protection Agency, Duluth, Minnesota \\ §ENTRIX, Saskatoon, Saskatchewan, Canada \\ $\|$ Michigan State University, East Lansing, Michigan, USA \\ \#Pacific Northwest National Laboratory, Sequim, Washington, USA \\ ††University of Florida, Gainesville, Florida, USA \\ $\ddagger \ddagger$ National Oceanic and Atmospheric Administration Fisheries, Seattle, Washington, USA \\ $\S \S$ RIFCON, Heidelberg, Germany
}

(Submitted 14 September 2009; Revised 28 November 2009; Accepted 2 March 2010)

\begin{abstract}
Maintaining the viability of populations of plants and animals is a key focus for environmental regulation. Population-level responses integrate the cumulative effects of chemical stressors on individuals as those individuals interact with and are affected by their conspecifics, competitors, predators, prey, habitat, and other biotic and abiotic factors. Models of population-level effects of contaminants can integrate information from lower levels of biological organization and feed that information into higher-level community and ecosystem models. As individual-level endpoints are used to predict population responses, this requires that biological responses at lower levels of organization be translated into a form that is usable by the population modeler. In the current study, we describe how mechanistic data, as captured in adverse outcome pathways (AOPs), can be translated into modeling focused on population-level risk assessments. First, we describe the regulatory context surrounding population modeling, risk assessment and the emerging role of AOPs. Then we present a succinct overview of different approaches to population modeling and discuss the types of data needed for these models. We describe how different key biological processes measured at the level of the individual serve as the linkage, or bridge, between AOPs and predictions of population status, including consideration of community-level interactions and genetic adaptation. Several case examples illustrate the potential for use of AOPs in population modeling and predictive ecotoxicology. Finally, we make recommendations for focusing toxicity studies to produce the quantitative data needed to define AOPs and to facilitate their incorporation into population modeling. Environ. Toxicol. Chem. 2011;30:64-76. (C) 2010 SETAC
\end{abstract}

Keywords-Risk assessment Chemical toxicity Adverse outcome pathway Population model Pellston workshop

\section{INTRODUCTION}

A recent report from the U.S. National Research Council (NRC) entitled "Toxicity Testing in the 21st Century: A Vision and a Strategy" ([1]; http://www.nap.edu/) describes challenges facing scientists responsible for determining human health effects of toxic chemicals and proposes a path forward designed to increase testing efficiency and reduce uncertainties associated with prediction of chemical risk. A critical focus of this proposed approach is incorporating mechanistic toxicology data into the risk assessment process. Many of the same challenges described by the NRC report for human health toxicology are also applicable to regulatory ecotoxicology. For example, one must consider the potential ecotoxicity of an increasing number of chemicals to meet new legislative mandates, while better focusing and reducing uncertainty of data collection associated with extant testing programs [2]. For human health assessments, mechanistic data could play a role in meeting these ecological risk assessment challenges [3]. Human

Presented at the SETAC Pellston Workshop, Forest Grove, OR, USA, April 18-23, 2009.

* To whom correspondence may be addressed

(vjkramer@dow.com).

Published online 20 October 2010 in Wiley Online Library (wileyonlinelibrary.com). health and ecological risk assessments have important differences, however, that must be considered in light of the U.S. National Academy of Sciences recommendations. One of these is the focal point of the assessment. The goal of human health assessments is to protect the individual. Conversely, although testing to support ecological risk assessments for chemicals usually is conducted at the level of the individual, the goal of these assessments typically is to protect the status of populations. Hence, the results of laboratory testing need to be translated into predictions of population status.

The continuing persistence of populations is a key concern for environmental regulations [4-7]. Population-level responses integrate the cumulative effects of chemical stressors on individuals as those individuals interact with and are affected by their conspecifics, competitors, predators, prey, habitat, and other biotic and abiotic factors. The interactions of populations within communities across landscapes constitute a functioning ecosystem. Models of population-level contaminant effects, therefore, can integrate information from lower levels of biological organization and feed that integrated information, if needed, into higher-level landscape and ecosystem models.

In the current study, we describe how quantitative mechanistic data, as defined in adverse outcome pathways (AOPs) $[8,9]$, can be placed into a computational framework and translated into population-level modeling that can be used in subsequent population-level risk assessment. An AOP has been 


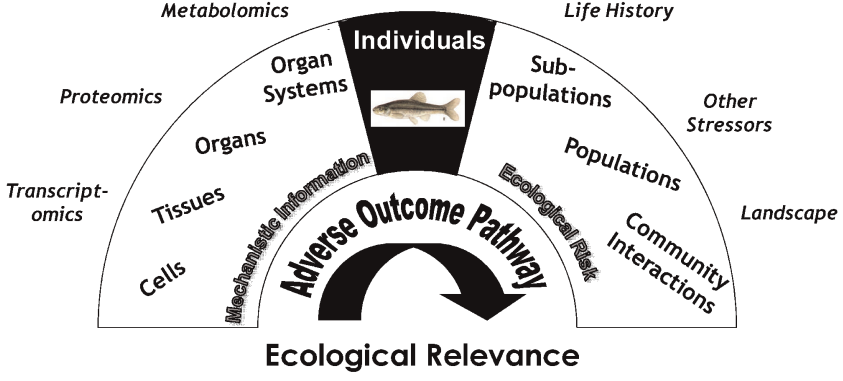

Fig. 1. Role of the individual organism in relating adverse outcome pathways (AOPs) to ecologically relevant levels of biological organization. The "-omics" tools provide data to support identification of AOPs, whereas life-history, landscape, and other biotic and abiotic stressors provide context to the population-level models built on the individual organism response.

defined by Ankley et al.[8] (page 730) as "a conceptual construct that portrays existing knowledge concerning the linkage between a direct molecular initiating event and an adverse outcome at a biological level of organization relevant to risk assessment." The AOP approach we discuss here translates mechanistic data to individual-level data centered on key outcomes related to survival and reproduction that can be quantitatively linked to population models (Fig. 1).

\section{REGULATORY CONTEXT}

Ecological risk assessments within regulatory frameworks are tailored to fit decision-making needs, quality of available data, and legally mandated protection goals. Protection and risk assessment for individual organisms is one approach taken in the management of endangered species [10,11]. However, other regulatory frameworks such as those governing wastewater discharge permits, manufacture of new chemicals, and pesticide registration, for example, take into consideration the assessment of the magnitude, duration, and severity of effects on individuals as these factors relate to the impact on the long-term viability and continuing persistence of populations [12]. The context of the population within the landscape and ecosystem of interest also should be taken into account, because these factors can impose spatial and resource limitations on populations. Simplified conservative ecological risk assessments often are the starting points for regulatory decision making. These first-tier assessments seek to protect populations by considering effects on individuals through the application of standardized safety factors to endpoints derived from laboratory studies such as acute mortality and measures of individual lifetime reproductive success. Population modeling is not considered in first-tier risk assessments. Higher-tier assessments can be employed when the first-tier assessments suggest potentially unacceptable risk to the individuals and by extension the populations under consideration. Often, these higher-tier assessments employ empirical measures of population-level responses determined through laboratory, semi-field, and field studies. Population models, especially those informed by AOPs, could be employed to generalize the results of these highertier studies to other landscapes and exposure situations and, in the absence of higher-tier studies, provide a means of translating individual-level study results to population-level responses.

Estimates of the ecological risk of environmental contaminants are based on responses in toxicity studies on individuals that are translated into possible population-level effects through a series of assumptions and safety factors. For example, mortality or chronic effects on growth or reproduction as observed in a standard laboratory exposure setting with a standardized species are assumed to provide the information needed to set standards to protect untested wild species of all age classes under all environmental conditions, as long as an adequate margin of safety is built into the risk assessment process. Quantitative mechanistic toxicological data, as encompassed by AOPs, collected at lower biological levels of organization could play a critical role in strengthening confidence in regulatory ecotoxicology and risk assessment.

Through understanding toxic mechanisms, more effectively extrapolating chemical effects across species, thereby reducing risk assessment uncertainty and enhancing environmental protection, should be possible [13]. An understanding of chemical mechanism of action also forms the basis for crosschemical extrapolation, using approaches such as read-across or quantitative structure-activity relationship modeling [14]. In the absence of experimental studies of mixtures, knowledge of toxicity mechanisms can inform the prediction of effects of chemical mixtures, thereby suggesting whether a risk assessment should be based on cumulative rather than single chemical exposures. Also, mechanistic information enables the development of hypothesis-based testing approaches, in which potentially sensitive species and endpoints can be targeted for testing, thereby better focusing limited resources and possibly reducing animal use. Despite these potential benefits, the historical drawback to mechanistic toxicology has been an inability to translate this information into endpoints useful for predicting risk at the population level. The challenge and goal, therefore, is effectively translating quantitative mechanistic AOP data to higher-level responses meaningful to population modeling and ecological risk assessment. A conceptual framework to support this translation is the AOP $[8,9]$.

Risk assessors need to consider whether a risk assessment prediction based on population modeling is reliable and realistic. In this context, model validation is a critical requirement [15]. A recent review [16] indicated that, of 40 models developed for pesticide risk assessment, testing, verification, or validation were not considered in $70 \%$ of them. One factor that can explain this discrepancy is that most models were not explicitly designed for regulatory decision making. Risk assessors should specifically address the validity and representativeness of the population models used, and, if AOPs are incorporated into the models, how that mechanistic information affects model performance.

Successful integration of AOPs into population models used in a regulatory context will require models for both forward simulation and parameter estimation [17]. In forward simulation, population models predict population state-variables conditional on a set of estimated model parameters such as demographic rates and their functional relationship to AOPs. Demographic projection, population forecasting, and population viability analysis are common examples of forward simulation. In parameter estimation, data pertaining to population state variables are used to estimate individual-level demographic parameters such as survival, reproduction, and growth rates. Mark-recapture studies, nest-survival estimates, and age-structure surveys are common methods for retrospective analysis. Historically, parameter estimation techniques have tended to come from statistical estimation theory and likelihood analysis, whereas forward simulation techniques have employed differential equations, matrix analysis, and simulation methods based on random number generators. This has resulted in different mathematical methods for forward simulation versus estimation and the potential for incompatibility 
between estimated demographic parameters and projection models in which they are used. In a population context, Clark [18] advocated the development of a common set of mathematical methods for prospective and retrospective modeling. In an ecotoxicological context, for example, Bennett and Etterson [19] have developed a unified mathematical framework for prospective and retrospective analysis of avian reproductive success.

\section{SURVEY OF POPULATION MODELS}

A wide variety of population models have been used in ecological risk assessments. Population models integrate births, deaths, immigration, and emigration to predict the future behavior of a population or to detect previous or current adverse effects on population productivity or structure. Different types of models can include more or less biological detail related to population class structure, physiological responses, density factors, stochasticity, and spatial information [20]. Numerous reviews delve into the intricacies, strengths, and weaknesses of the various types of population models that have been applied to ecological risk assessment. Although a large number of population models are available for almost any taxonomic group, the question of how to perform risk assessments with population models is still under debate. A complete discussion about which population-level endpoints may be used and how risk assessments that incorporate population modeling shall be performed is beyond the scope of this article. For further discussion, refer to Barnthouse et al. [7], Munns et al. [21], Pastorok et al. [22,23], Thorbek et al. [24], or Wang and Grimm [25]. Each type of model serves to answer specific questions related to abundance, productivity, viability, extinction, and recovery while having different data requirements, assumptions, generality, realism, and regulatory applicability [21]. Some general constructs that could integrate AOP information include ordinary differential equations, structured demographic (life-history) models, individual-based models, and dynamic energy budget models. These models can incorporate density dependence, and environmental stochasticity, and most can be adapted as spatially explicit models.

One of the simplest forms of modeling population dynamics is through ordinary differential equation models, also called scalar or unstructured models. Such models apply rate of change (birth, death, immigration, emigration rates per unit of population such as the individual or biomass) to assess the potential changes in the population over time. Unstructured models have limited data requirements or assume a uniform population without demographic or environmental structure. One example commonly used in fisheries management is the Ricker model, which incorporates a density-dependent factor when computing the population abundance at the next time step [26]. Unstructured models are often used for screening-level assessments or when few stage-specific/ age-specific data are available.

Structured demographic population models incorporate the biological structure of the population by assessing demographic rates of a progression of cohorts usually classed by age or life stage. The most common of these structured models assign vital rates of survival or reproductive contribution to each class. The tools of matrix algebra are used to examine class structure, the intrinsic population growth rate, and the life stages that drive the population growth rate, and to predict future abundance [27]. Life history models require a reasonably good understanding of the natural history of the target population and intermediate amounts of data to provide generality, realism, and accuracy. For example, not all life history strategies respond to a stressor to the same extent, and therefore, differences in life-history strategies should be considered in population-level risk assessments [28,29]. Another source of toxicity data to feed into structured models can come from life table response experiments that track survival and reproductive rates for the entire life cycle of organisms in laboratory or field experiments [30].

Individual-based models (IBMs), as the name suggests, model the survival, productivity, and movement of each individual in the population during its entire life span $[31,32]$. These models can be highly specific with regard to site and demographic rates and can include physiological states of each individual. This provides ample opportunity and flexibility to develop highly specific models that can address detailed questions related to AOPs. The IBMs have substantial data requirements but can produce models with high levels of realism and accuracy. These models are often population and site specific, and applying such models to other populations or locations without extensive reparameterization [21] can be difficult.

Dynamic energy budget models treat organisms as dynamic physical systems with explicit mass and energy balances. The modeling is based on ordinary differential equations and defines a set of rules for how organisms acquire and use energy [33]. Dynamic energy budget models operate at the level of the individual and have the potential to incorporate AOPs by assessing changes in bioenergetics: toxicant effects on maintenance costs such as compensation/adaptation; decreased assimilation of energy from food; increased energetic costs for growing new body tissue; increased energetic costs for producing offspring; and costs to the developing embryo [34]. Outputs from dynamic energy budget models include essential life history information such as reproductive endpoints and stage-specific mortality, which can then be used to model population dynamics. Such modeling has been proposed for cross-species extrapolation by using just a few parameters to describe a broad spectrum of life-history patterns [33].

\section{SURVEY OF ECOTOXICITY STUDIES}

Traditionally toxicity tests have not been designed to explicitly collect data for population modeling but, rather, for efficiency. Tests typically employ short-term exposures of organisms with short generation times to measure endpoints such as survival and reproductive output. In the hierarchy of biological levels of organization, the individual organism serves as the keystone spanning functional inputs arising from molecular, cellular, and organ levels as well as contextual constraints arising from ecosystem, landscape, and population levels (Fig. 1). Population models necessarily incorporate these inputs and constraints as they make predictions about the ability of the individual to survive and reproduce. However, current testing strategies and regulatory approaches differ significantly in the generation and utilization of toxicity test data useful for population models to support chemical risk assessments. Differences include duration of exposure, realism of test conditions, endpoints measured, and life stages tested. For example, because of their short reproductive cycles, assays with invertebrates tend to be conducted more frequently over multiple generations, whereas tests with many vertebrate species, including most fish species, amphibians, birds, or mammals, are often limited to partial or single-generation tests because of their longer life spans [35].

Life cycle studies are considered relevant for assessing the long-term risks associated with the exposure of a population to pollutants. Vertebrates (fish) and invertebrates including crus- 
tacean, insect, arachnid, bivalve, and annelid species have been frequently used in life cycle studies (Table 1). A life cycle test typically exposes an animal at a minimum from the embryo stage of the parental generation to the embryo stage of the offspring. In some cases, especially for vertebrates, this requires testing over extended periods ranging from several months to multiple years, which limits the practicality of such assays and often makes them prohibitively expensive. Furthermore, the representation of species for which life cycle tests exist is somewhat limited. In this context, whether results of life-cycle assays in the standard, commonly-tested species (e.g., in the case of fish, fathead minnow [Pimephales promelas], medaka [Oryzias latipes], and zebrafish [Danio rerio]) can be extrapolated to longer-lived species that cannot be tested in the laboratory remain to be determined, perhaps in part through the population modeling approaches described herein.

Standard toxicity tests have been developed for most phyla of the animal kingdom (Table 1). Most of these tests use species that can be readily cultured under controlled conditions and that are characterized by rather short generation times. Furthermore, many of the assays used in ecological risk assessment were adapted from clinical animal models not necessarily representing indicator species of interest in context with environmental issues. For example, with respect to responses to dioxin-like compounds acting through the aryl hydrocarbon receptor, the standard laboratory models can have very different sensitivities when compared with wild species of concern [36,37].

Toxicity tests exist for both terrestrial and aquatic species. Predominant terrestrial invertebrate test species include annelid worms and arthropods [38], and, for vertebrates, quail, mallard duck, chicken, rat, mouse, and hamster often represent birds and mammals, respectively. Although efforts have been made to establish amphibian and reptile models for use in terrestrial ecological risk assessment, internationally standardized tests have not been developed [39]. For aquatic species, standardized tests covering endpoints related to teratogenicity, reproduction, or the entire life cycle are available for fish, frogs, crustaceans, insects, and annelids through efforts by agencies such as the U.S. Environmental Protection Agency (http://www.epa. gov/opptsfrs/publications/), the Organisation for Economic Cooperation and Development (http://masetto.sourceoecd.org) and the American Society for Testing and Materials (http:// www.astm.org/BOOKSTORE/).

Toxicity tests can measure a variety of endpoints relating to individual fitness; however, application of these endpoints to models of population-level effects requires careful consideration of relationships among endpoints. Survival and reproductive endpoints can be directly applied to population model calculations of the respective vital rates. Other types of endpoints, such as measures of growth, behavior, development, and immune function, can be linked using empirically based mathematical relationships that could feed into survival or reproductive elements of a population model (Fig. 2). Many pathways can potentially influence these system nodes, and they can be a conduit of many types of information, including mechanistic toxicity data, to the vital rates used in population modeling. For maximum application across levels of biological organization, AOPs should encompass test endpoints or nodes that can be quantitatively related to demographic traits of the model population.

\section{ECOTOXICITY STUDIES AND AOPS}

Current toxicity tests have limitations with regard to generating data suitable for coupling AOPs with population mod- eling. For example, toxicity studies ideally should generate complete dose-response or concentration-response relationships for both lethal and sublethal effects, but this often does not or cannot occur in practice. Dose-response data are necessary to accurately define thresholds for effects, to describe the slope of the response, and to allow estimates of probability of effects from given exposures to segments of populations, including the individual. For example, most population models can extrapolate effects from traditional toxicity tests that generate median lethality/effects values (i.e., median lethal dose, median lethal concentration, and half maximal effective concentration data), when the slope of the response curve is available. Population models usually incorporate these data as percentage reductions in parameter values for given exposure concentrations. However, robust population modeling relying on how an organism will perform in natural settings requires more information than simply whether it is alive or dead at a given contaminant concentration. Mesa et al. [40] used the term ecological death, distinguished from laboratory death, to take into consideration scenarios in which exposure causes significant alterations in behavior or physiology such that the organism is unable to function in its ecological role. For example, in standardized reproduction toxicity tests, the reproductive output of an organism provides information on how many offspring the individual has the potential to produce, which provides a direct link to reproductive AOPs. However, information may be missing on whether the individual will be able to successfully attract mates, guard territories, or raise offspring. Male competition experiments [41] offer one alternative to enhance reproduction toxicity studies for use in developing AOPs and for population modeling. Also, the degree of secondary sex characteristic expression also could be potentially linked, either correlatively or causatively, depending on the strength of the underlying mechanistic data, to reproductive success, thereby building the AOP bridge between behavioral measurements and individual reproductive success [42].

Other AOP nodes such as growth, development, and immune function can be equally complex and difficult to interpret from simple toxicity experiments. For example, growth as an endpoint in traditional toxicity tests is difficult to interpret without proper context. In laboratory settings, food is usually unlimited; therefore, impairment in growth in these experiments may not adequately describe a disruption in an ecologically relevant physiological mechanism [43]. To assess whether impairment in growth is a likely outcome in the field, organisms could be placed in situations in which they compete for food with unexposed organisms and forage in the presence of predation [44]. Many ecological processes are size-based, such as reproduction and stage-specific survival, and a more thorough empirical representation of effects on growth than enabled by most current toxicity tests would provide better estimates of survival and reproduction to the population models. For example, developmental delays associated with reduced growth can lead to increased probability of mortality by increasing the amount of time an individual spends in a vulnerable stage [45]. Contaminant-induced immune suppression could translate into reduced growth because of increased energetic costs associated with parasitism or infectious disease [46].

The collection and processing of data from traditional doseresponse experiments can be designed with the model in mind. For example, individual-based models incorporate behavior and bioenergetics and demand significant quantities of data to be collected on individuals. Toxicity experiments could be designed so that key individualized data could be collected, 


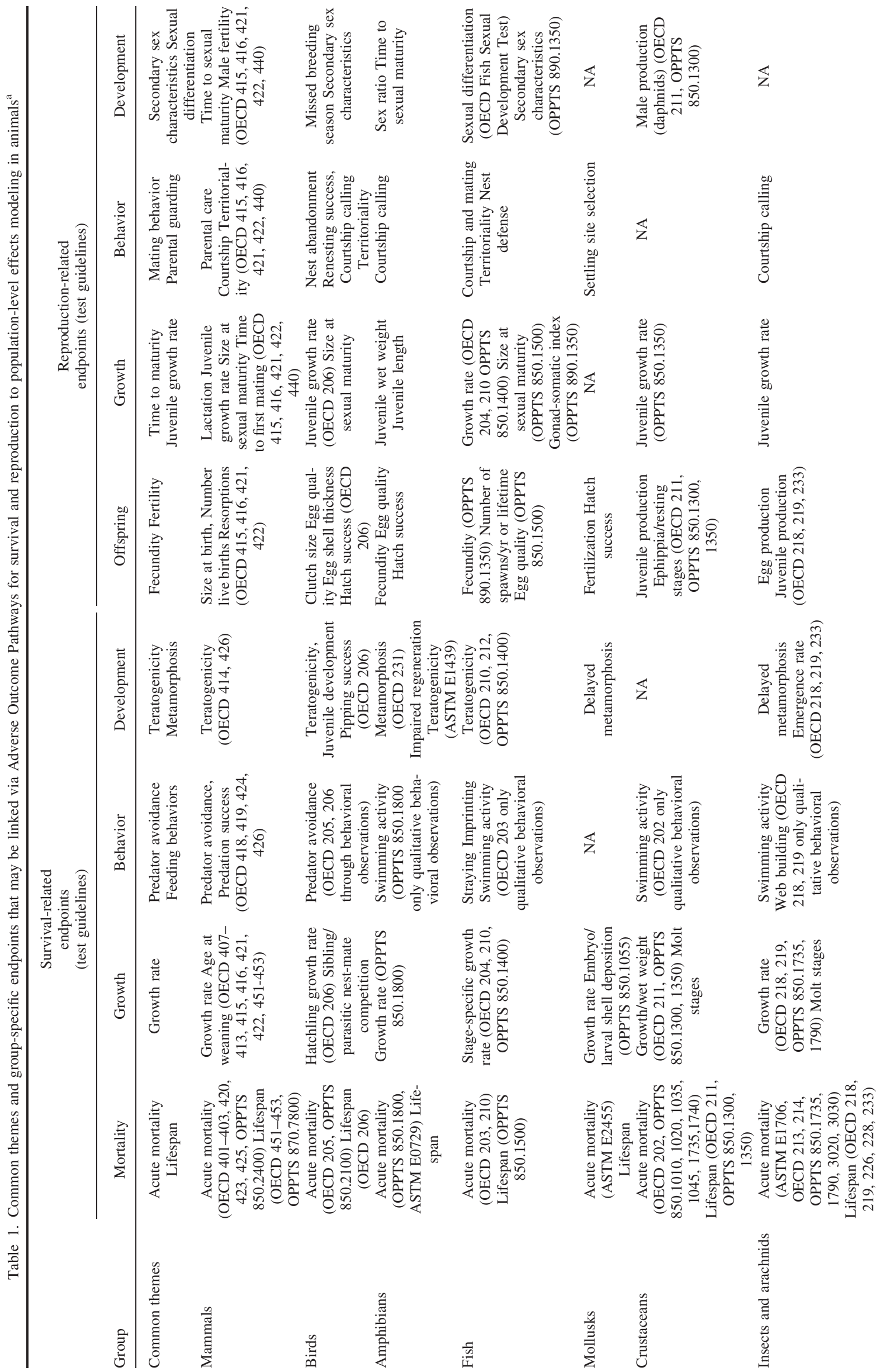




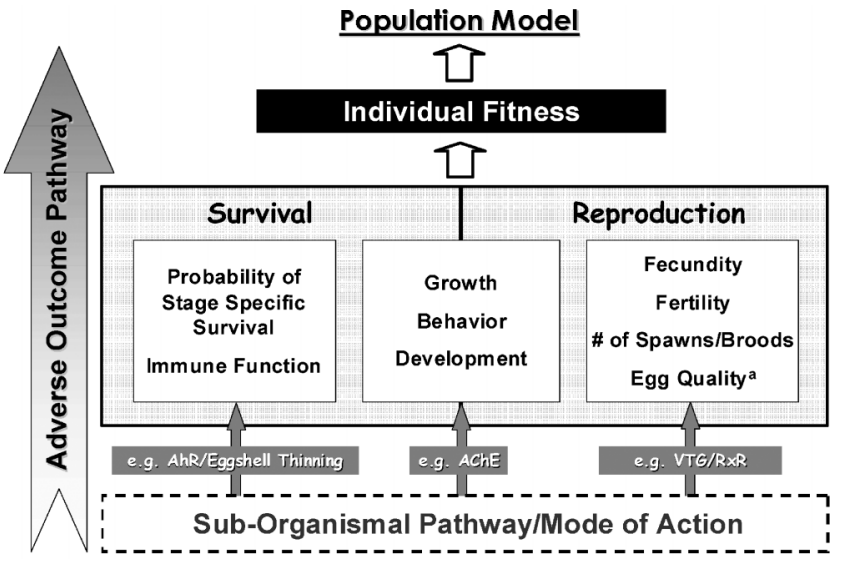

Fig. 2. Simplified illustration of the concept of adverse outcome pathways linking suborganismal pathways with population modeling approaches. White boxes represent "system nodes" connecting suborganismal pathways with apical endpoints (survival and reproduction). ${ }^{a}$ Specific to oviparous animals. Gray-shaded boxes: Examples of critical molecular pathways predicting effects at the node level. $\mathrm{AhR}=$ aryl hydrocarbon receptor, $\mathrm{AChE}=$ acetylcholine esterase; $\mathrm{VTG}=$ vitellogenin; $\mathrm{RxR}=$ retinoid $\mathrm{X}$ receptor.

but it must be done without making such studies unwieldy and prohibitively expensive. Standardization of the methods of data collection will be a key factor to bring such observations into practical usage. One important advantage to individualized observations is the explicit measurement of variability in individual response, which can be incorporated into IBMs to provide better modeling over the range of possible responses [47].

\section{INDIVIDUAL ORGANISMS AND AOPS}

The AOP metrics associated with responses that manifest at the level of individuals are the fitness parameters needed to model the response of populations. Thus, for maximal utility to population modeling, AOPs that consider the relationship between exposure, dose, and adverse response need ultimately to track to either survival or reproduction. The lower-level organismal effects, for example, immune function, metabolic rate, growth, development, behavior, fecundity, and fertility, track to outcomes related to survival or reproduction as measured at the level of the individual. These organismal level effects might integrate one or more AOPs associated with different mechanisms of action. As such, the AOPs can be characterized via different patterns of molecular, biochemical, and cellular responses reflective of initiating events leading to toxicity. Ultimately, through survival and reproduction, the individual is the keystone that cements the mechanistic processes that underlie organismal-level function to the higher-order population-level effects elucidated through population modeling.

To achieve this bridging of biological and ecological hierarchies, the metrics of effect at the level of mechanistic detail must be connected in a causal chain to those used to assess individual condition. In turn, the individual organism metrics ultimately must be expressed in terms of effects on survival and reproduction to provide the input data needed for populationlevel effects modeling. This requires that models that describe lower-level mechanistic detail be coupled with those being used for modeling population processes and necessitates empirically derived quantitative relationships between the individual endpoint and inputs to the demographic rates of the population models. Establishing these relationships often requires simul- 
taneous bottom-up and top-down integration of the physiology of the organism with the natural history of the population. For example, the bottom-up pathway may lead to reduced growth for the individual, and the top-down pathway may lead to an understanding that survival and reproductive rates are influenced by body size. These relationships will guide how the data on the individual response should be appropriately integrated into the population model.

Individual-level functional responses describe the link between AOPs and population-level effects. These individual-level functional responses must accomplish two important tasks. First, they need to describe a dose-response relationship in which the response variable has a known-ideally quantifiable-relationship to survival or reproductive success. For example, in the eggshell thinning case described later, a quantitative dose-response relationship between the toxicant and eggshell thickness would be of limited value unless the probability of egg breakage and egg viability as a function of shell thickness are quantitatively linked. Second, the individual-level functional responses also must integrate the laboratory-generated dose-response function with field-generated ecological data pertaining to the same demographic endpoint. For example, a dose-response for survival in a laboratory test may be integrated with field estimates of background mortality by using the theory of competing risks [48] to properly account for the nonadditive nature of mortality effects. Such functional responses can be used in a matrix modeling framework, in which the parameterized individual-level functions are inserted into the appropriate cells of the projection matrix. Stark et al. [49] show, using life-table analysis, that multiple effects on both survival and reproduction of beneficial insect populations must be integrated to account for greater than predicted observed population-level effects.

The key challenge for establishing AOPs is to align the mechanistic data obtained by means of genomic or other suborganismal studies with apical endpoints that are required for the application of population models, namely, survival and reproduction. This can be done by using critical endpoints that are specific to certain vital pathways, so-called system nodes.
For example, vitellogenin (VTG; egg yolk protein) production by females is a prerequisite for successful egg production in egg-laying vertebrates [50]. These vital pathways end in a physiological condition that is directly linked to survival and reproductive success. System nodes can integrate multiple suborganismal pathways such as estrogen receptor antagonism, decreased estrogen synthesis, and increased estrogen metabolism, all leading to the reduction of VTG in females as a predictor of reduced fecundity (Fig. 3).

A significant challenge, therefore, is to identify the molecular pathways and endpoints that enable the prediction of effects at the system node level. In the subsequent section, a series of examples are provided that illustrate several attempts to characterize some AOPs relative to linking molecular initiating events to outcomes at the individual level that subsequently can be evaluated in terms of population-level consequences.

The following examples focus on AOPs in fish, birds, and an invertebrate species. For an AOP case example involving mammals, Watanabe et al. [51] provide an illustrative description of the effects of domoic acid on wild populations of mammals.

\section{Case 1: Inhibition of vitellogenesis}

An example of how mechanistic data can be linked to prediction of population status through responses at the individual level involves the physiological process of vitellogenesis in female teleost fish [50]. Vitellogenin is produced in the liver of oviparous vertebrates through activation of the estrogen receptor by endogenous estradiol $\left(\mathrm{E}_{2}\right)$. From the liver, VTG is transported via the blood to the ovary, where it is processed and incorporated into oocytes as the primary biomass and energy source for the developing embryo. As a consequence, stressors that affect vitellogenesis have the potential to directly impact fecundity and egg quality. A number of established chemical mechanisms exist whereby VTG production can be depressed, including antagonism of the estrogen receptor, that is, blocking activation by $E_{2}$, indirect feedback inhibition of the production of sex steroids, including $E_{2}$, by agonists of the androgen receptor, and direct depression of steroid production
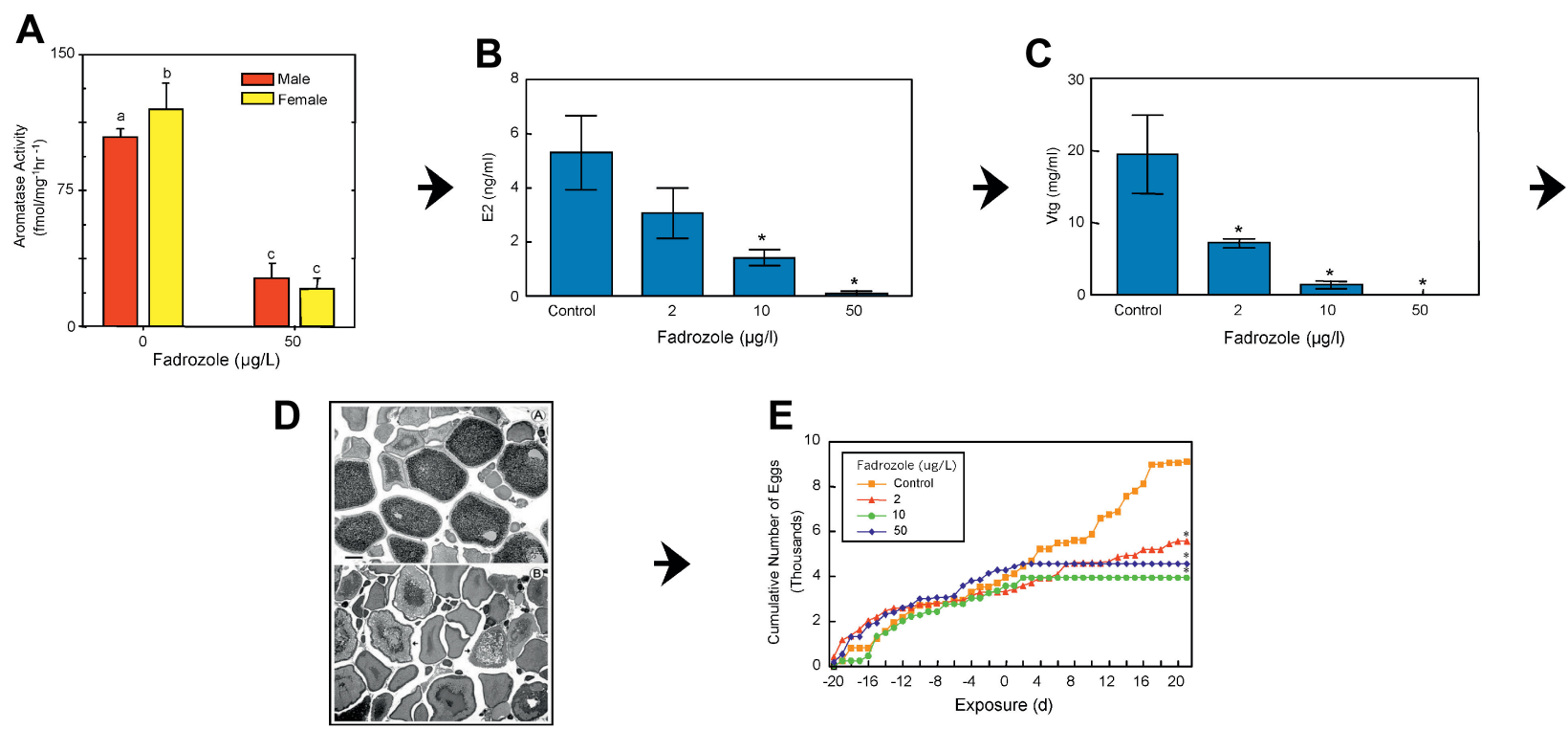

Fig. 3. An adverse outcome pathway in fish [2,50]. Aromatase inhibitor example. (A) Aromatase inhibition by fadrozole; (B) Reduction in circulating estradiol; (C) Reduction in circulating vitellogenin (Vtg); (D) Histopathology of ovarian tissue, top panel normal ovary, bottom panel fadrozole treated; note oocyte atresia; (E) Adverse outcome on egg production-fecundity (C) Elsevier, Used with permission,) 
by chemicals that inhibit key enzymes involved in the steroid synthesis pathway [50]. Hence, VTG status is a robust biochemical indicator of the effects of chemical exposures with different mechanisms of action on fish endocrine function. Figure 3 (adapted from Ankley et al. [2]) provides an example of how this relationship can be visualized as an AOP starting with inhibition of aromatase, the enzyme that converts testosterone to E2. In this example, fadrozole, a classical inhibitor of aromatase, is shown to depress activity of the enzyme in exposed fathead minnows (Fig. 3, panel 1), thereby depressing plasma $\mathrm{E}_{2}$ and VTG concentrations (Fig. 3, panels 2 and 3), which decreases deposition of VTG to developing oocytes (Fig. 3, panel 4) and, ultimately, depresses egg production by the fish (Fig. 3, panel 5).

Vitellogenesis is a key physiological node for multiple AOPs and, as such, has been used as a basis for prospective population modeling. For example, Murphy et al. [52,53] developed predictive models of hypoxia, $\mathrm{Cd}$, and polychlorinated biphenyl impacts on Atlantic croaker populations through evaluation of effects of those two substances on vitellogenesis. Miller et al. [50] used toxicity data from fathead minnow reproduction experiments with five chemicals with differing mechanisms of action to develop a quantitative relationship between vitellogenesis and fecundity and used this relationship as the basis for a predictive population model. The approaches described by Murphy et al. [52,53] and Miller et al. [50] demonstrate how mechanistic toxicology data can be integrated through effects at the individual level to population-level predictions.

\section{Case 2: Aryl hydrocarbon receptor}

This case example demonstrates how mechanistic toxicological information can be applied to a retrospective analysis of chemical effects at the population level. A number of planar halogenated hydrocarbons, including certain polychlorinated biphenyls (PCBs), polychlorinated dibenzo- $p$-dioxins (PCDDs), and polychlorinated dibenzofurans, bind to and activate the vertebrate aryl hydrocarbon receptor (AhR), resulting in a wide array of tissue- and species-specific effects, which can be especially pronounced during early development. A relatively well-characterized response to AhR agonists in developing salmonid fish is a lethal condition termed blue sac disease [54]. Although the cascade of biochemical and physiological events linking activation of the AhR to blue sac disease are not fully defined, the relationship between activation of the receptor and early-life-stage mortality nonetheless has proved sufficient to conduct a robust retrospective assessment of effects of planar halogenated hydrocarbons on a Great Lakes lake trout population [55].

Coincident with established decreases in numbers of lake trout in Lake Ontario in past decades, blue sac disease has been observed in embryos spawned from adult fish collected from the system. To assess the possible role of PCB, polychlorinated dibenzofuran, and PCDD contamination in causing this, Cook et al. [55] reconstructed a historical exposure record of Lake Ontario lake trout to the mixture of AhR agonists present in the lake, using a combination of empirical sediment:tissue residue relationships and radio-dating approaches through analysis of sediment core samples. Based on potency (receptor binding or activation) of the different PCBs, polychlorinated dibenzofurans, and PCDDs in the sediments, they converted the exposure information for the mixture into a single potency value (assuming additivity based on the common AOP) calibrated to 2,3,7,8tetrachlorodebenzo- $p$-dioxin. Historic survival of the lake trout embryos then could be indexed to measured toxicity of 2,3,7,8- tetrachlorodebenzo- $p$-dioxin to developing embryos in controlled laboratory studies. Cook et al. [55] compared their temporal exposure and toxicity predictions with historic commercial lake trout harvest data for Lake Ontario. They observed a strong correlation between predicted occurrence of early-lifestage mortality of the fish and observed harvest data and also reported indications of some degree of recent recovery of the lake trout population, associated perhaps with natural burial of historically contaminated sediments. Overall, the case made by Cook et al. [55] for the legacy effects of PCBs, polychlorinated dibenzofurans, and PCDDs on lake trout population status was achieved through an understanding of an AOP for AhR-related contaminants.

\section{Case 3: Acetylcholinesterase}

Organophosphate and carbamate pesticides inhibit acetylcholinesterase, an enzyme that regulates neurotransmittermediated signaling at synapses. An individual-based model was developed based on empirical data that explicitly links sublethal reductions in acetylcholinesterase activity to reductions in feeding behavior, food consumption, growth, and size at outmigration of sub-yearling chinook salmon (Oncorhynchus tshawytscha; [56]). Individual size was used to estimate sizedependent sub-yearling survival during the migration and transition to the sea. These individual survival estimates were then integrated into a life-history population matrix and used to predict reductions in population productivity and growth rate. Overall, the population model is based on an AOP relating acetylcholinesterase inhibition to feeding behavior in salmon [57] that predicts reductions in somatic growth rates in individual fish. The key link between changes in the somatic growth rate and the parameters needed as inputs to the life-history population model was the identification and quantification of the relationship between a change in size (length) to a change in sub-yearling survival derived from a long-term field study [58].

\section{Case 4: Calcium-adenosine triphosphatase}

In birds, an example of an AOP comes from the inhibition of Ca-dependent adenosine triphosphate synthase, resulting in reduced calcium transport to the oviduct [59] and thinner eggshells. Lincer [60] quantified a dose-response relationship between dietary dichlorodiphenyldichloroethylene (a metabolite of dichlorodiphenyltrichloroethane) and eggshell thickness in American kestrels (Falco sparverius) and further indicated that eggs began to break under the weight of incubation when they were more than $22 \%$ thinner than unexposed eggs. The consequences to avian populations of this eggshell thinning are not initially obvious, for several reasons. First, the effect is expressed as a threshold beyond which effects begin to occur (eggs break). From a modeling perspective, expressing the probability of egg-breakage as a function of exposure would be more useful. Second, American kestrels, like many birds, readily re-nest after clutch failure. Thus, a female's seasonal productivity depends on the success of all her nest attempts during a breeding season, which could counter the potential losses to egg breakage. Finally, predicted egg breakage attributable to dichlorodiphenyldichloroethylene must be integrated with natural rates of nest failure attributable to other causes.

These difficulties highlight an important aspect of the main thesis: AOPs can be transduced to populations through effects in individuals. Successful modeling of this transduction requires an understanding of the individual-level processes influenced by the AOP. In this case, a statistical model of avian nest survival coupled with an iterative model of the re-nesting 
process is needed. Like population models, these survival and re-nesting models may be simple or complex, depending on the data and the population to be modeled. Bennett and Etterson [19,61] developed a Markov process model specifically designed for chemical risk assessment, but other modeling frameworks are possible $[62,63]$.

This example also provides a cautionary note concerning the generality of AOPs across species, because vulnerability to eggshell thinning from dichlorodiphenyldichloroethylene is not consistent across orders of birds (Falconiformes and Pelecaniformes) and not across Passeriformes, the most species-rich avian order, or Galliformes. The explanations for differential vulnerability remain to be elucidated, but they likely include both species differences in the physiological pathway (i.e., the $\mathrm{AOP})$ and differences in exposure.

\section{Case 5: Retinoid-X-receptor}

Exposure of gastropods to bis(tri- $n$-butyltin) can result in a masculinization phenomenon called imposex, the development of a vas deferens or penis in females, which has been linked to population decline and local extinction [64]. However, the precise biochemical cause of imposex is poorly characterized $[65,66]$. Although bis(tri- $n$-butyltin) apparently inhibits aromatase, limiting the conversion of testosterone to $\mathrm{E}_{2}$ [67], whether all species subject to imposex express a functional estrogen receptor [68], suggesting that estrogens may not have a causal role in the development of imposex, is unknown. A new linkage has been proposed between imposex and the retinoid-X-receptor, a member of the nuclear hormone receptor superfamily for which the natural ligand is 9-cis-retinoic acid. Although species differences likely exist, an equivalent dose of 9-cis retinoic acid or bis(tri- $n$-butyltin) results in a similar degree of imposex and penis development in Nucella lapillus [65]. To date, no attempt has been made to model the effect of imposex on fecundity in a gastropod population. However, a proposed AOP for imposex development could provide a number of useful endpoints for population modelers. For example, exposure to sufficient concentrations of bis(tri- $n$-butyltin) could result in a molecular cascade initiated by retinoid-X-receptor signaling, ultimately manifesting itself in the development of a penis or vas deferens in female snails. The development of these structures in females could be hypothesized to reduce fecundity in females. Given further characterization of the retinoid-X-receptor signaling cascade in gastropods, the possibility exists that the level of expression of one or more transcripts could be correlated with fecundity, making those gene expression data useful for population modeling. Therefore, this is a case in which improved characterization of the AOP at the molecular level could enhance the ability of population modelers to predict adverse outcomes at the population level, by linking the molecular response to the population response through individual fecundity.

\section{CHALLENGES FACING ECOLOGICAL RISK ASSESSMENT}

\section{Ecological relevance of $A O P S$}

Data currently in the literature include a large number of mechanistic responses to toxicants at the molecular, biochemical, and cellular levels that may or may not be significant in terms of defining changes in individuals that could be translated into adverse effects at the population level. The key is to define those pathways that are pertinent to population-level risk assessments. A thorough review of existing data, to best characterize AOPs at the level of the individual and below, would produce quantitative relationships between responses at lower levels of organization and individual survival and fecundity, improving the understanding of adverse outcomes at the population level [50]. Furthermore, the melding of genomics data and toxicity studies might allow researchers to better connect the expression of genes, proteins, and small molecules with survival and reproduction, perhaps discovering pathways that are currently undefined. For example, using a reproduction-focused medaka PCR array, Zhang et al. [69] developed a hepatic transcription index composed of six transcripts in the liver, the expression of which revealed a log-linear relationship with fecundity. These molecular data, although correlative, could prove useful for population modeling, provided the empirical relationship between transcriptional status and fecundity could be shown to be reflective of a causal pathway. In the absence of knowledge about the functional role of transcripts that happen to respond to a treatment, a more generalized analysis could still be used to identify those transcripts that are shown to be predictive of toxic effects. Such informative patterns can be ascertained by using a variety of network analysis tools [70]. Although outside of the field of toxicology, a very complete approach to identifying regulatory networks in yeast was employed by Zhu et al. [71]. That study used functional enrichment analysis of gene ontology, gene expression-quantitative trait loci analysis, transcription factor-binding site data, and protein-protein interactions across the entire genome of yeast to identify informative patterns in gene expression. These kinds of network analyses, when applied to genomic data produced in ecotoxicology studies, would allow for better characterization of key pathways at levels below the individual and provide the basis for predictive, and ultimately causal, linkage to adverse outcomes. Eventually, these efforts could populate the ecotoxicology data with mechanistic predictors of effects on reproduction and survival that are useful for population modeling and ecological risk assessment.

\section{Parameterizing population models}

When modeling the population-level response attributable to subtle or sublethal effects on individuals, preferred constructs are often structured demographic models, IBMs, or dynamic energy budget models that can potentially delineate responses and indicate causal relationships. These models often require substantial amounts of basic biological information. Finding the data needed to parameterize the models can be difficult because of the amount of detail needed and the limited availability of the data for most species and populations. For example, structured demographic models require information on number of functional life stages, connection, and duration; survival within and between stages; and the reproductive contributions of each life stage. Acquiring all of the necessary data from a single population requires extensive field monitoring for multiple generations to get an appropriate, statistically robust estimate of the transitions. Some populations pose problems in this regard because of life span, habitat use, and migratory habits, and logistics of handling, quantifying, and staging individuals. Gathering the necessary data for a single population is so rarely completed that most models incorporate data from multiple populations of the same species that have the same life-history strategy and inhabit nearby locations. This adds to the uncertainty of model output, because each population has adapted to local conditions, and those adaptations may contribute to different responses. Even for a given population, some combined datasets may cover a broad temporal range (e.g., several decades). Costs and time are the limiting factors in resolving 
these types of uncertainties. Support for continuing long-term monitoring of populations of interest for different regions, taxa, and exposure potential would greatly increase the confidence and applicability of the model outputs. In addition, promoting studies on natural history and demographics of new species of interest could rapidly expand the ability to investigate AOPs across diverse species.

The key to applying individual endpoint responses to changes in population dynamics is having an empirically based mathematical relationship between the measured endpoint and the demographic parameter. Some are straightforward, such as changes in the clutch size of each female serving as a direct input into calculating bird fecundity. Other relationships, especially involving behavior, growth, and survival, may require field studies to establish or support the mathematical relationships used. Expanding the test species used for identifying and confirming AOPs to those needed for population modeling would help reduce the cross-species and cross-taxa extrapolation that can be necessary. For example, rather than extrapolating from studies in the standard Chironomus species, conducting toxicity studies on field-collected Trichoptera caddisfly species could help define AOPs in the context of the lifehistory attributes of the population of interest [72].

\section{Variability and uncertainty}

Predictive models are generally parameterized based on empirical data obtained from laboratory trials or field studies. Separate trial results vary partly because of natural differences between samples or organisms (natural variability) and because of sampling effects and methodological constraints (uncertainty). Although the need for estimating uncertainty and variability were recognized early in the advent of population ecology [73-75], these factors are not commonly addressed explicitly in population models (for exceptions see $[18,76]$ ). However, in a regulatory context, knowing to what extent variability is included in a model and how certain one can be of a prediction is important. A model may cover the entire variability observed in the field, or it may be based on parameters that reflect rather specific test conditions of one or a few studies. Notably, many life-history parameters may vary remarkably in the field. For example, in birds, egg numbers and body weights often vary geographically, or population cycles may be present in some populations whereas they are absent in others [16]. Because of limited data availability, producing a model that is representative for all circumstances is not always possible, and these limitations need to be acknowledged.

Distinguishing between variability and uncertainty is often difficult, because both have an impact on the variance of the test results. If parameters are measured empirically, then standard deviations or other measures of variance often include information about both variability and uncertainty. However, uncertainty also may be related to unknown mechanisms or the absence of data on how expression of an AOP might be influenced by differing exposure scenarios. In many cases how laboratory-derived AOP data can be reliably transferred to field conditions may not be clear. A clear formulation of what the model exactly represents can help to clarify possible limitations. Methods to include uncertainty and variability in models, such as Monte Carlo simulation, are available [18]. For applying these methods, the data used for parameterization (e.g., associated with key AOP nodes) must include information about variability and uncertainty. As an example, the prediction from a pathway model that a decrease in VTG production of
$50 \%$ would decrease fecundity by $40 \%$ in fish [50] would be useful in a population model and could then take the entire range of possible individual effects into account. The combination of several uncertainties in different parts of a model can result in a considerable amount of uncertainty in the overall prediction of the entire model because of multiplication of error. However, a full discussion of propagation of error in modeling, and methods to control and account for it, are beyond the scope of this article (see Clark [18]).

\section{Multigenerational responses}

Natural populations can experience exposure to contaminants that persist for multiple generations, and evolutionary adaptation has been demonstrated involving pesticides [77]; aromatic hydrocarbon contaminants, including PCBs and PCDDs [78]; and heavy metals [79]. Contaminant exposure can reduce fitness in exposed populations via effects on individual survival or reproduction, and selection can act on the capacity of individuals to tolerate the toxicant. The survivors can be those individuals with increased resistance to toxicity, leaving a population with overall greater resistance to exposure [80].

Adaptation to toxic chemical exposure may require only a few genes to enable a rapid shift in the mean response to toxicity, a hypothesis that is supported by studies on metals and organic toxicants [81-83]. The relationship between enhanced tolerance and the responsible genes may provide connectivity between molecular responses to toxicants and responses at higher levels of biological organization. Thus, studies on the evolution of differential tolerance may provide valuable insights into mechanisms that underlie ecological and evolutionary responses to chemical stress, with the potential of identifying effects that ultimately transcend single generations and extend the notion of AOPs to evolutionary change that can alter the characteristics of populations.

The extent of adaptive change is limited by the genome, and adaptive change can result from one or more of several factors that include toxicity to molecular targets and the extent to which expression of targets can be modified to counteract the effects of a contaminant; the expression of resistance genes and their mechanisms for regulation; enhanced expression of genes displaying copy number variation as a result of duplicated genes; and selection for new variants of proteins that confer advantage. Copy number variation that arises from gene duplication and retention of duplicated genes is recognized as a feature associated with increased genome complexity [84]; increased expression attributable to duplicated resistance genes, and mutations in paralogs, which confer increased resistance, can be the basis of increased resistance to contaminants. To illustrate, the following represent examples of contaminant-resistant populations: cyclodiene-resistant mosquitofish possess resistant forms of the toxicity targets, that is, gamma-aminobutyric acid and diazepam receptors [85]; point mutations in the acetylcholinesterase gene confer increased resistance to organophosphorus and carbamate insecticides in field strains of Drosophila melanogaster, and recombination of existing alleles carrying such mutations leads to rapid adaptation to insecticide exposure [86]; overexpression of a single cytochrome P450 allele is associated with resistance to a variety of insecticides in Drosophila melanogaster [87] and amplification of an esterase gene involved in insecticide detoxification confers insecticide resistance in a Culex mosquito [88]; and duplication of a metallothionein gene is associated with increased metal resistance in Drosophila melanogaster [89]. The heritability of these mech- 
anisms of resistance serves as the basis for extrapolation of AOPs across evolutionary trajectories. In Daphnia magna, enhanced resistance to the insecticide cyfluthrin and the hydrocarbon naphthalene, likely related to expression of cytochrome p450s, was observed after four generations of a 12-generation exposure and declined to control levels over 12 generations after cessation of exposure [90]. Differences in population metrics such as survival time, time to first brood, and total offspring number were not seen between control and resistant lines when measured in the first generation postexposure and thereafter [90]. In this case, a fitness-related phenotype associated with the resistance genes was not seen, a contingent response that could be accounted for in population models.

Stress induced by the presence of a contaminant is also superimposed on adaptation to the suite of natural stressors already present in a particular environment [82]. A recognized cost for such adaptation is increased susceptibility to other environmental stresses [91]. In fish exposed to Cd over several generations, adapted individuals have been shown to exhibit deterioration in fitness metrics such as reduced fecundity, reduced size of offspring, longer time to first reproduction, and reduced life expectancy in females. The fitness costs and tradeoffs may result from maintenance of the underlying resistance mechanisms, leading to changes in internal resource allocation [92].

Heritable characteristics of single species and their expression can have outcomes that affect community and ecosystem level processes, and changes in the latter can, in turn, alter the genomic composition of that species in a feedback loop that affects the expression of genes in that species [93,94]. The accumulation of such changes in the metagenome of complex assemblages can have implications in the structure and function of communities and ecosystems. Key processes embedded in the expression of specific genes have implications for AOPs that may extend from individual to community-level interactions.

\section{Community interactions}

In ecological risk assessment, potential effects of a contaminant on the habitat used by a population may need to be addressed [95]. These indirect effects involve community-level interactions such as predator-prey relationships, resource competition, successional processes, and trophic cascades (bottomup or top-down control). For example, a contaminant may not have a direct impact on a bird population through a defined AOP in the birds, but it could indirectly affect the population by adversely affecting availability of the invertebrate food supply [40]. In this case, to understand population-level effects in the target species of concern, knowledge of AOPs in the invertebrates may be required.

For the protection of endangered species in the United States, community-level effects are routinely incorporated into the assessment $[10,11]$. Some important population endpoints that feed into community modeling could consist of measures of population abundance through time, such as between seasons and between years, age structure and distribution, reproductive output with age, population spatial variability, population cyclicity, and density-dependent relationships such as parasitism and disease transmission. Consideration of community-level effects can be incorporated into a population model implicitly or explicitly. Implicitly, the population model parameter is assumed to include the community effect. For example, the effects of impaired behavior on the ability to capture food and avoid predators can be incorporated by using an individualbased model to calculate a new dose-response curve based on these community interactions [96,97]. If an AOP can be delineated that links the impaired behavior at the level of the individual to the community-level interaction, then through the modified IBM framework, community-level effects may be addressed. Explicitly, an extra term or function on the parameters can be based on an observed community response. For example, if a contaminant was demonstrated to alter the abundance of the food source of an organism, the carrying capacity of the population model could be adjusted as a function of contaminant concentration. An AOP that links the contaminant effect on a prey species to its population abundance could be a linkage to community-level effects [95-97]. Hence, AOPs could be applied to multiple species interactions.

\section{CONCLUSIONS}

The AOP concept represents a new paradigm in the interpretation and use of quantitative mechanistic ecotoxicology data. By building biologically robust linkages between molecular initiating events and adverse outcomes, AOPs can become a central organizing principle in ecotoxicology research. Much remains to be done to realize this potential, and the few examples provided herein offer a first glimpse at a road map for the role of predictive ecotoxicology in population-level risk assessment. Additional avenues of research to explore include further elucidating AOPs involving diverse, ecologically relevant modes of action; defining the relative importance of potentially different AOPs arising from the same chemical as modified by dose, duration of exposure, or life-stage sensitivity; and quantitative comparison of the efficiency of AOP-based population modeling and risk assessment with traditional methods. Relative to this latter goal, empirical data generated in laboratory testing must meet the requirements of not only mechanistic toxicology but also population modeling. Finally, the need continues for baseline biological information for taxa of interest such that population models reflect the multiple physiological and ecological interactions that modulate adverse responses to chemical stressors.

Population modeling facilitates the translation of laboratorycollected toxicity data into predictions of effects relevant to ecological risk assessment. However, to achieve this in a seamless manner, the appropriate types of toxicity data must be collected. Specifically, endpoints from toxicity tests need to reflect, in a quantitative manner, the key vital functions of survival and reproduction. This does not mean that mechanistic molecular, biochemical, and subcellular responses are not useful to population-level risk assessments, but it does dictate that these types of responses need to be linked to higher-level impacts in the individual that then bridge to population-level effects. The AOP framework does this by enhancing identification and visualization of these linkages. Population models cover a range of complexity that can be suited to the regulatory or research needs and the extent of data available on life-history parameters. Modeling effects on the individual through AOPs provides the keystone that links the bottom-up toxicity information with the top-down information on population dynamics, community interactions, and, ultimately, ecosystem influences.

Acknowledgement - This work was supported by the Society for Environmental Toxicology and Chemistry, U.S. Army Corps of Engineers Engineer Research and Development Center Program in Environmental Quality and Installations, the Natural Environment Research Council, the U.S. EPA, and Procter \& Gamble. This document has been subjected to review by the U.S. EPA, National Health and Environmental Effects Research Laboratory, and 
approved for publication. Approval does not signify that the contents reflect Agency views or policies.

\section{REFERENCES}

1. Krewski D. 2007. Toxicity Testing in the 21st Century: A Vision and a Strategy. Committee on Toxicity Testing and Assessment of Environmental Agents. National Academies Press, Washington, DC, USA.

2. Ankley GT, Bencic D, Breen M, Collette TW, Connolly R, Denslow ND, Edwards S, Ekman DR, Jensen KM, Lazorchak J, Martinovic D, Miller DH, Perkins EJ, Orlando EF, Garcia-Reyero N, Villeneuve D, Wang RL, Watanabe K. 2009. Endocrine disrupting chemicals in fish: developing exposure indicators and predictive models of effects based on mechanisms of action. Aquat Toxicol 92:168-178.

3. Bradbury SP, Feijtel TC, Van Leeuwen CJ. 2004. Meeting the scientific needs of ecological risk assessment in a regulatory context. Environ Sci Technol 38:463A-470A.

4. U.S. Environmental Protection Agency. 1998. Guidelines for ecological risk assessment. EPA/630/R-95/002F. Duluth, MN, USA

5. Reiter L. 2005. Wildlife research strategy. EPA 600/R-04/050. U.S. Environmental Protection Agency, Research Triangle Park, NC.

6. European Commission Health and Consumer Protection DirectorateGeneral. 2002. Draft working document guidance document on terrestrial ecotoxicology under council directive 91/414/EEC. SANCO/10329/2002 Rev. 2 Final. Brussels, Belgium.

7. Barnthouse LW, Munns WR, Sorenson MT. 2007. Population Level Ecological Risk Assessment. CRC, Boca Raton, FL, USA.

8. Ankley GT, Bennett RS, Erickson RJ, Hoff DJ, Hornung MW, Johnson RD, Mount DR, Nichols JW, Russom CL, Schmieder PK, Serrano JA, Tietge JE, Villeneuve DL. 2010. Adverse outcome pathways: A conceptual framework to support ecotoxicology research and risk assessment. Environ Toxicol Chem 29:730-741.

9. Villeneuve DL, Garcia-Reyero N. 2011. A vision and strategy for predictive ecotoxicology testing in the 21st century. Environ Toxicol Chem 30:1-8 (this issue).

10. U.S. Fish and Wildlife Service, National Oceanographic and Atmospheric Administration. 1994. Endangered and Threatened Wildlife and Plants: Notice of Interagency Cooperative Policy for Endangered Species Act Section 9-Prohibitions. Fed Reg: 59:34272.

11. National Oceanic and Atmospheric Administration. 1999. Endangered and threatened wildlife and plants: Definition of "harm'. 50 CFR Part 222. Fed Reg 64: 60727-6073 2 .

12. Ellis JB. 2000. Risk assessment approaches for ecosystem responses to transient pollution events in urban receiving waters. Chemosphere 41:85-91.

13. Bus JS, Canady RA, Collier TK, Owens JW, Pettit SD, Scholz NL, Street AC. 2007. The extension of molecular and computational information to risk assessment and regulatory decision making. In Benson WH, DiGiulio RT, eds Genomic Approaches for Cross-Species Extrapolation In Toxicology. SETAC Press, Pensacola, FL, USA, pp 151-175.

14. Bradbury SP, Russom CL, Ankley GT, Schultz TW, Walker JD. 2003. Overview of data and conceptual approaches for derivation of quantitative structure-activity relationships for ecotoxicological effects of organic chemicals. Environ Toxicol Chem 22:1789-1798.

15. Bart J. 1995. Acceptance criteria for using individual-based models to make management decisions. Ecol Appl 5:411-420.

16. Grimm V, Thorbek P, Schmolke A, Chapman P. 2009. State-of-the-art of ecological modelling for pesticide risk assessment: A critical review. In Thorbek P, Forbes VE, Heimbach F, Hommen U, Thulke H-H, van den Brink PJ, Wogram J, Grimm V, eds, Ecological Models for Regulatory Risk Assessments of Pesticides, Developing a Strategy for the Future. SETAC, Boca Raton, FL, USA, pp. 77-88.

17. Clark JS. 2007. Models for Ecological Data. Princeton University, Princeton, NJ, USA.

18. Clark J. 2003. Uncertainty and variability in demography and population growth: A hierarchical approach. Ecology 84:1370-1381.

19. Bennett RS, Etterson MA. 2007. Incorporating results of avian toxicity tests into a model of annual reproductive success. Integr Environ Assess Manag 3:498-507.

20. Rose KA, Adamack AT, Murphy CA, Sable SE, Kolesar SA, Craig JK, Breitburg DL, Thomas P, Brouwer MH, Cerco CF, Diamond S. 2009. Does hypoxia have population-level effects on coastal fish? Musing from the virtual world. J Exp Mar Biol Ecol 381:S188-S203.

21. Munns WR, Gervais J, Hoffman AA, Hommen U, Nacci DE, Nakamaru M, Sibly R, Topping CJ. 2008. Modeling approaches to population-level ecological risk assessment. In Barnthouse LW, Munns WR, Sorenson
MT, eds, Population-Level Ecological Risk Assessment. CRC, Boca Raton, FL, USA, pp 179-210.

22. Pastorok RA, Akcakaya R, Regan H, Ferson S, Bartell SM. 2003. Role of ecological modeling in risk assessment. Hum Ecol Risk Assess 9:939972.

23. Pastorok RA, Bartell SM, Ferson S, Ginzburg LR. 2002. Ecological Modeling in Risk Assessment: Chemical Effects on Populations, Ecosystems, and Landscapes. CRC, Boca Raton, FL, USA.

24. Thorbek P, Forbes VE, Heimbach F, Hommen U, Thulke H-H, Van den Brink PJ, Wogram J, Grimm V. 2009. Ecological Models for Regulatory Risk Assessments of Pesticides: Developing a Strategy for the Future. SETAC, Pensacola, FL, USA.

25. Wang M, Grimm V. 2010. Population models in pesticide risk assessment: Lessons for assessing population-level effects, recovery and alternative exposure scenarios from modelling a small mammal. Environ Toxicol Chem 29:1292-1300.

26. Ricker WE. 1954. Stock and recruitment. J Fish Res Board Canada 11:559-623.

27. Caswell H. 2001. Matrix Population Models: Construction, Analysis, and Interpretation, 2nd ed. Sinauer Associates, Sunderland, MA, USA

28. Spromberg JA, Birge WJ. 2005. Modeling the effects of chronic toxicity on fish populations: The influence of life-history strategies. Environ Toxicol Chem 24:1532-1540.

29. Stark JD, Banks JE, Vargas R. 2004. How risky is risk assessment: The role that life history strategies play in susceptibility of species to stress. PNAS 101:732-736.

30. Caswell H. 2000. Life table response experiments in ecotoxicology. In Kammega J, Laskowski R, eds Demography in Ecotoxicology. John Wiley \& Sons, New York, NY, USA, pp 43-55.

31. Wang M, Grimm V. 2007. Home range dynamics and population regulation: An individual-based model of the common shrew Sorex araneus. Ecol Model 205:397-405.

32. Railsback SF, Harvey BC. 2002. Analysis of habitat selection rules using an individual-based model. Ecology 83:1817-1830.

33. Nisbet RM, Mueller EB, Lika K, Kooijman SALM. 2000. From molecules to ecosystems through dynamic energy budgets. J Anim Ecol 69:913-926.

34. Jager T, Heugens EH, Kooijman SA. 2006. Making sense of ecotoxicological test results: towards application of process-based models. Ecotoxicology 15:305-314.

35. Maciorowski HD, Clarke RM. 1980. Advantages and disadvantages of using invertebrates in toxicity testing. In Buikeman AL, Cairns J, eds Aquatic Invertebrate Bioassays. STP 715. American Society for Testing and Materials, Philadelphia, PA, pp 36-47.

36. Hahn ME. 1998. Mechanisms of innate and acquired resistance to dioxinlike compounds. Rev Toxicol 2:395-443.

37. Karchner SI, Franks DG, Kennedy SW, Hahn ME. 2006. The molecular basis for differential dioxin sensitivity in birds: role of the aryl hydrocarbon receptor. Proc Natl Acad Sci U S A 103:6252-6257.

38. Leeuwen CJ, Vermeire TG. 2007. Risk Assessment of Chemicals: An Introduction 2nd ed. Springer, Heidelberg, Germany.

39. Suter GW, Efroymson RA, Sample BE, Jones DS. 2000. Ecological Risk Assessments for Contaminated Sites. CRC, Boca Raton, FL, USA.

40. Mesa MG, Poe TP, Gadomski DM, Petersen JH. 1994. Are all prey created equal? A review and synthesis of differential predation on prey in substandard condition. J Fish Biol 45 (suppl A): 81-96.

41. Zheng W, Strobeck C, Stacey N. 1997. The steroid pheromone 4pregnen-17,20ss-diol-3-one increases fertility and paternity in goldfish J Exp Biol 200:2833-2840.

42. Jacob A, Evanno G, Renai E, Sermier R, Wedekind C. 2009. Male body size and breeding tubercles are both linked to intrasexual dominance and reproductive success in the minnow. Anim Behav 77:823-829.

43. Alvarez Mdel C, Murphy CA, Rose KA, McCarthy ID, Fuiman LA. 2006. Maternal body burdens of methylmercury impair survival skills of offspring in Atlantic croaker (Micropogonias undulatus). Aquat Toxicol 80:329-337.

44. Relyea RA. 2003. Predator cues and pesticides: A double dose of danger for amphibians. Ecol Appl 13:1515-1521.

45. Churchfield S, Hollier J, Brown VK. 1995. Population dynamics and survivorship patterns in the common shrew Sorex araneus in Southern England. Acta Theriol 40:53-68.

46. Morand S, Harvey PH. 2000. Mammalian metabolism, longevity and parasite species richness. Proc Biol Sci 267:1999-2003.

47. DeAngelis DL, Mooij WM. 2005. Individual-based modeling of ecological and evolutionary processes. Annu Rev Ecol Evol Syst 36:147-168. 
48. Etterson MA, Nagy LR, Rodden-Robinson T. 2007. Partitioning risk among different causes of nest-failure. Auk 124:432-443.

49. Stark JD, Vargas R, Banks JE. 2007. Incorporating ecologically relevant measures of pesticide effect for estimating the compatibility of pesticides and biocontrol agents. J Econ Entomol 100:1027-1032.

50. Miller DH, Jensen KM, Villeneuve DL, Kahl MD, Makynen EA, Durhan EJ, Ankley GT. 2007. Linkage of biochemical responses to populationlevel effects: A case study with vitellogenin in the fathead minnow (Pimephales promelas). Environ Toxicol Chem 26:521-527.

51. Watanabe KH, Andersen ME, Basu N, Carvan MJ, Crofton KM, King KA, Sunol C, Tiffany-Castiglioni E, Schultz IR. 2011. Defining and modeling known adverse outcome pathways: Domoic acid and neuronal signaling as a case study. Environ Toxicol Chem 30:9-21 (this issue).

52. Murphy CA, Rose KA, Rahman MS, Thomas P. 2009. Testing and applying a fish vitellogenesis model to evaluate laboratory and field biomarkers of endocrine disruption in atlantic croaker (Micropogonias undulatus) exposed to hypoxia. Environ Toxicol Chem 28:1288-1303.

53. Murphy CA, Rose KA, Thomas P. 2005. Modeling vitellogenesis in female fish exposed to environmental stressors: Predicting the effects of endocrine disturbance due to exposure to a PCB mixture and cadmium. Reprod Toxicol 19:395-409.

54. U.S. Environmental Protection Agency. 1993. Interim report on data and methods for assessment of 2,3,7,8-tetrachlorodibenzo- $p$-dioxin risks to aquatic life and associated wildlife. EPA-600/R-93/055. Duluth, MN.

55. Cook PM, Robbins JA, Endicott DD, Lodge KB, Guiney PD, Walker MK, Zabel EW, Peterson RE. 2003. Effects of aryl hydrocarbon receptor-mediated early life stage toxicity on lake trout populations in Lake Ontario during the. 20th. century. Environ Sci Technol 37:38643877.

56. Baldwin DH, Spromberg JA, Collier TK, Scholz NL. 2009. A fish of many scales: Extrapolating sublethal pesticide exposures to the productivity of wild salmon populations. Ecol Appl 19:2004-2015.

57. Sandahl JF, Baldwin DH, Jenkins JJ, Scholz NL. 2005. Comparative thresholds for acetylcholinesterase inhibition and behavioral impairment in coho salmon exposed to chlorpyrifos. Environ Toxicol Chem 24:136145.

58. Zabel RW, Achord S. 2004. Relating size of juveniles to survival within and among populations of Chinook salmon. Ecology 85:795-806.

59. Khan HM, Cutkomp LK. 1982. In vitro studies of DDT, DDE, and ATPase as related to avian eggshell thinning. Arch Environ Contam Toxicol 11:627-633.

60. Lincer JL. 1975. DDE-induced eggshell-thinning in American kestrels: A comparison of the field situation and laboratory results. J Appl Ecol 12:781-793.

61. Bennett RS, Etterson MA. 2006. Estimating pesticide effects on fecundity rates of wild birds using current laboratory reproduction tests. Hum Ecol Risk Assess 12:762-781.

62. Cowardin LM, Johnson DH. 1979. Mathematics and mallard management. J Wildl Manag 43:18-35.

63. Pease CM, Grzybowski JA. 1995. Assessing the consequences of brood parasitism and nest predation on seasonal fecundity in passerine birds. Auk 112:343-363.

64. Gibbs P, Bryan G. 1987. TBT paints and the demise of the dog-whelk, Nucella lapillus (Gastropoda). Oceans 19:1482-1487.

65. Castro LF, Lima D, Machado A, Melo C, Hiromori Y, Nishikawa J, Nakanishi T, Reis-Henriques MA, Santos MM. 2007. Imposex induction is mediated through the retinoid $\mathrm{X}$ receptor signalling pathway in the neogastropod Nucella lapillus. Aquat Toxicol 85:57-66.

66. Oehlmann J, Di Benedetto P, Tillmann M, Duft M, Oetken M, SchulteOehlmann U. 2007. Endocrine disruption in prosobranch molluscs: Evidence and ecological relevance. Ecotoxicology 16:29-43.

67. Oehlmann J, Markert B, Stroben E, Schulte-Oehlmann U, Bauer B, Fioroni P. 1996. Tributyltin biomonitoring using prosobranchs as sentinel organisms. Anal Bioanal Chem 354:540-545.

68. Iguchi T, Watanabe H, Katsu Y. 2006. Application of ecotoxicogenomics for studying endocrine disruption in vertebrates and invertebrates. Environ Health Perspect 114 (Suppl 1): 101-105.

69. Zhang X, Hecker M, Tompsett AR, Park JW, Jones PD, Newsted J, Au D, Kong R, Wu RS, Giesy JP. 2008. Responses of the medaka HPG axis PCR array and reproduction to prochloraz and ketoconazole. Environ Sci Technol 42:6762-6769.

70. Perkins EJ, Chipman K, Edwards S, Habib T, Falciani F, Taylor R, Van Aggelen G, Vulpe C, Antczak P, Loguinov A. 2011. Reverse engineering adverse outcome pathways. Environ Toxicol Chem 30:22-38 (this issue).

71. Zhu J, Zhang B, Smith EN, Drees B, Brem RB, Kruglyak L, Bumgarner RE, Schadt EE. 2008. Integrating large-scale functional genomic data to dissect the complexity of yeast regulatory networks. Nat Genet 40:854 861

72. Johnson KR, Jepson PC, Jenkins JJ. 2008. Esfenvalerate-induced caseabandonment in the larvae of the caddisfly (Brachycentrus americanus). Environ Toxicol Chem 27:397-403.

73. Andrewartha HG, Birch LC. 1954. The Distribution and Abundance of Animals. University of Chicago Press, Chicago, IL, USA.

74. Strong DR. 1986. Density vagueness: Abiding the variance in the demography of real populations. In Diamond J, Case TJ, eds, Community Ecology. Harper and Row, Cambridge, UK, pp 257-268.

75. Turchin P. 1995. Population regulation: Old arguments and a new synthesis. In Cappuccino N, Price PW, eds, Population Dynamics: New Approaches and Synthesis. Academic, San Diego, CA, USA.

76. Wiegand T, Revilla E, Knauer F. 2004. Dealing with uncertainty in spatially explicit population models. Biodiversity Conserv 13:53-78.

77. Roush R, McKenzie J. 1987. Ecological genetics of insecticide and acaricide resistance. Annu Rev Entomol 32:361-380.

78. Wirgin I, Waldman JR. 2004. Resistance to contaminants in North American fish populations. Mutat Res 552:73-100.

79. Antonovics J, Bradshaw A, Turner R. 1971. Heavy metal tolerance in plants. Adv Ecol Res 7:1-85.

80. Salice CJ, Miller TJ, Roesijadi G. 2009. Demographic responses to multigeneration cadmium exposure in two strains of the freshwater gastropod, Biomphalaria glabrata. Arch Environ Contam Toxicol 56:785-795.

81. Macnair MR. 1991. Why the evolution of resistance to antropogenic toxins normally involves major gene changes: the limits to natural selection. Genetica 84:213-219.

82. Salice CJ, Roesijadi G. 2002. Resistance to cadmium and parasite infection are inversely related in two strains of a freshwater gastropod. Environ Toxicol Chem 21:1398-1403.

83. Yarbrough JD, Roush R, Bonner JC, Wise DA. 1986. Monogenic inheritance of cyclodiene insecticide resistance in mosquitofish, Gambusia affinis. Experientia 42:851-853.

84. Lynch M, Conery JS. 2003. The origins of genome complexity. Science 302:1401-1404.

85. Bonner JC, Yarbrough JD. 1988. Vertebrate cyclodiene insecticide resistance: Role of gamma-aminobutyric acid and diazepam bindingsites. Arch Toxicol 62:311-315

86. Mutero A, Pralavorio M, Bride JM, Fournier D. 1994. Resistanceassociated point mutations in insecticide-insensitive acetylcholinesterase. Proc Natl Acad Sci USA 91:5922-5926.

87. Daborn PJ, Yen JL, Bogwitz MR, Le Goff G, Feil E, Jeffers S, Tijet N, Perry T, Heckel D, Batterham P, Feyereisen R, Wilson TG, FrenchConstant RH. 2002. A single P450 allele associated with insecticide resistance in Drosophila. Science 297:2253-2256.

88. Mouches C, Pasteur N, Berge JB, Hyrien O, Raymond M, Desaintvincent BR, Desilvestri M, Georghiou GP. 1986. Amplification of an esterase gene is responsible for insecticide resistance in a California Culex mosquito. Science 233:778-780.

89. Maroni G, Wise J, Young JE, Otto E. 1987. Metallothionein gene duplications and metal tolerance in natural populations of Drosophila melanogaster. Genetics 117:739-744.

90. Brausch JM, Smith PN. 2009. Development of resistance to cyfluthrin and naphthalene among Daphnia magna. Ecotoxicology 18:600-609.

91. Meyer JN, Di Giulio RT. 2003. Heritable adaptation and fitness costs in killifish (Fundulus heteroclitus) inhabiting a polluted estuary. Ecol Appl 13:490-503.

92. Xie L, Klerks PL. 2004. Fitness cost of resistance to cadmium in the least killifish (Heterandria formosa). Environ Toxicol Chem 23:1499-1503.

93. Whitham TG, Bailey JK, Schweitzer JA, Shuster SM, Bangert RK, Leroy CJ, Lonsdorf EV, Allan GJ, DiFazio SP, Potts BM, Fischer DG, Gehring CA, Lindroth RL, Marks JC, Hart SC, Wimp GM, Wooley SC. 2006. A framework for community and ecosystem genetics: from genes to ecosystems. Nat Rev Genet 7:510-523.

94. Whitham TG, DiFazio SP, Schweitzer JA, Shuster SM, Allan GJ, Bailey JK, Woolbright SA. 2008. Perspective: Extending genomics to natural communities and ecosystems. Science 320:492-495.

95. Fleeger JW, Carman KR, Nisbet RM. 2003. Indirect effects of contaminants in aquatic ecosystems. Sci Total Environ 317:207-233.

96. Murphy CA, Rose KA, Alvarez Mdel C, Fuiman LA. 2008. Modeling larval fish behavior: Scaling the sublethal effects of methylmercury to population-relevant endpoints. Aquat Toxicol 86:470-484.

97. Macneale K, Kiffney P, Scholz N. 2010. Pesticides, aquatic food webs and the conservation of Pacific salmonids. Frontiers Ecol Environ 2010 DOI: $10.1890 / 090142$ 